\title{
Microscopy studies on magnetron sputtered thin films with preferred orientation for positron moderation
}

\author{
V.L. Ene 1, 2, A.B. Șerban ${ }^{2}$, V. Leca ${ }^{2}$, B.S. Vasile ${ }^{1}$, E. Andronescu 1,2,* \\ 1 University Politehnica of Bucharest, Faculty of Applied Chemistry and Materials Science, Gh. Polizu Street No. 1-7, \\ Bucharest, Romania \\ 2 Extreme Light Infrastructure - Nuclear Physics (ELI-NP), Horia Hulubei National R\&D Institute for Physics and Nuclear \\ Engineering, Reactorului Street No. 30, Magurele, Romania \\ * Correspondence: ecaterina.andronescu@upb.ro; Scopus ID: 57194217630
}

Doppler-broadening Spectroscopy (DBS) and positron annihilation lifetime spectroscopy (PALS) are two positron annihilation spectroscopy techniques used for identifying near surface vacancies and lattice dislocations. Positrons manifest a broad energy distribution of about several $\mathrm{MeV}$ and in order to generate a low-energy positron beam, the positrons need to pass through a material called "moderator" so that a narrow positron kinetic energy bandwidth can be obtained, without losing too much intensity. The moderator must possess certain properties, among which a large negative positron work function and a large branching ratio to free positrons. The first can be assessed to an intrinsic characteristic of the material, that is usually correlated to the material bandgap, and in order to attain the second, a defect free, epitaxial thin film should be obtained.

Due to its $3.4 \mathrm{eV}$ bandgap, GaN represents a very promising candidate for positron moderation and field assisted moderation, that might manage longer average positron diffusion lengths. The aim of the present study is to obtain semi-insulating $\mathrm{GaN}$ thin films by magnetron sputtering $\mathrm{GaN}$ on different substrates $\left(\mathrm{ZnO}, \mathrm{TiO}_{2}, \mathrm{Al}_{2} \mathrm{O}_{3}\right)$ with fewer impurities incorporated, which should hold promises of increasing the positron diffusion length in the material.

Preliminary depositions made in this study are to be discussed, highlighting both their advantages and limitations derived from their structure characterization.

Keywords: Doppler-broadening spectroscopy, DBS, magnetron sputtered thin films.

\section{Funding}

Not applicable.

\section{Acknowledgments}

Not applicable.

\section{Conflicts of Interest}

The authors declare no conflict of interest.

PROCEEDINGS INTERNATIONAL | https://conferenceproceedings.international | 62

Cite This Work: Ene, V.L.; Șerban, A.B.; Leca, V.; Vasile, B.S.; Andronescu, E. Microscopy studies on magnetron sputtered thin films with preferred orientation for positron moderation. Proceedings Int 2019 , 1, 0062-0063. https://doi.org/10.33263/Proceedings 11.00620063 
Microscopy studies on magnetron sputtered thin films with preferred orientation for positron moderation
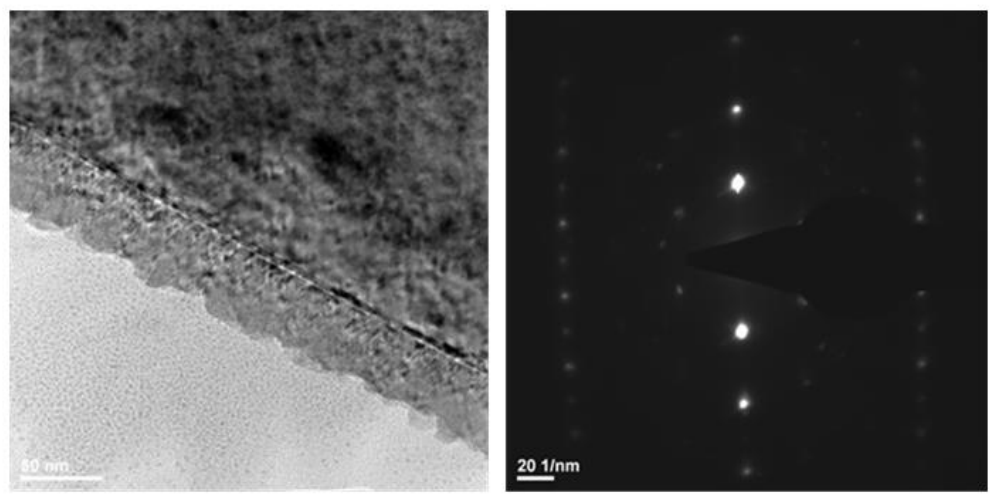

Figure 1. TEM and SAED images on the $\mathrm{GaN}-\mathrm{ZnO}$ interface.

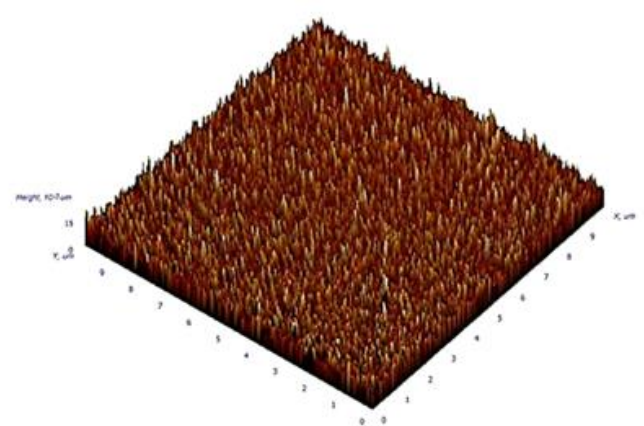

Figure 2. Atomic force microscopy on the $\mathrm{GaN}$ deposited on $\mathrm{ZnO}$.

\section{References}

1. Hugenschmidt, C. Positrons in surface physics. Surf. Appl. Surf. Sci. 1999, 149, 253-259, Sci. Rep. 2016, 71, 547-594, https://doi.org/10.1016/S0169-4332(99)00211-1. https://doi.org/10.1016/j.surfrep.2016.09.002.

2. Beling, C.D.; Fung, S.; Ming, L.; Gong, M.; Panda, B.K. A theoretical search for possible high efficiency semiconductor based field assisted positron moderators.

3. Kuech, T.F. III-V compound semiconductors: Growth and structures. Prog. Cryst. Growth Charact. Mater. 2016, 62, 352-370, https://doi.org/10.1016/j.pcrysgrow.2016.04.019.

(C) 2019 by the authors. This article is an open access article distributed under the terms and conditions of the Creative Commons Attribution (CC BY) license (http://creativecommons.org/licenses/by/4.0/). 